Revista de Ciencias Sociales - Número 63 (2013) - Páginas 13-52

Delicuencia, discurso y derechos. Para una topología...

\title{
DELINCUENCIA, DISCURSOS Y DERECHOS. PARA UNA TOPOLOGÍA SOBRE LA DELINCUENCIA EN CHILE
}

\section{CRIME, SPEECHES AND RIGHTS. TOPOLOGY FOR CRIME IN CHILE}

RODRIGO CALDERÓN ASTETE*

Programa de Post Graduación, Universidad Católica de Pelotas, Río Grande do

Sul, Brasil

rodrigocalderonster@gmail.com

\section{Resumen}

La delincuencia ocupa un lugar central en los discursos políticos y la prensa. De todo lo que se dice sobre los delitos y los criminales conviene analizar en detalle los discursos que se generan, las visiones de sociedad y de políticas públicas que en ellos se proponen. Este trabajo pretende describir y exponer esos discursos, discutir su supuesta cientificidad e independencia, descubrir cuál es la lógica que desde ellos se pretende imponer, el tipo de herramientas y soluciones anti delincuencia, para analizar de manera crítica le relación entre esas construcciones y el sistema jurídico, el estado de derecho, los derechos humanos y una sociedad incluyente que recupere la relación con quienes cometen delitos, su familia y su entorno.

* Abogado. Licenciado en Ciencias Jurídicas y Sociales por la Universidad de Concepción, Chile. Maestro en Derecho por la Universidad Internacional de Andalucía. Doctor en Derecho por la Universidad Pablo de Olavide de Sevilla. Artículo recibido el 6 de noviembre de 2013 y aceptado el 5 de diciembre de 2013.

Revista de Ciencias Sociales - Número 63 (2013) - Universidad de Valparáíso - ISSN 0716-7725-Valparaíso, Chile 


\title{
Palabras claves
} sociedad.

Delincuencia, discursos, política criminal, Derechos Humanos,

\begin{abstract}
Crime occupies a central place in the political speeches and the press. Everything that is said on the crimes and the criminals should be analyzed in detail the speeches that are generated, the visions of society and public policies that they propose. This work seeks to describe and expose those speeches, discuss their alleged scientific and independence, discover what logic since they seek to impose the kind of tools and solutions anti crime, to critically analyze you relationship between these constructions and the legal system, the rule of law, human rights and an inclusive society that retrieve the relationship with those who commit crimes, his family and your environment.
\end{abstract}

\section{Keywords}

Crime, speeches, criminal policy, Human Rights, society.

\section{Introducción}

Existen problemas difíciles de conocer y acometer, por la complejidad social en que están inmersos y se cogeneran con ella pero además por cantidad de juicios, antejuicios y prejuicios con que se les piensa y habla, por su exposición pública y la disputa que a través de ellos se hace en el campo político. Uno de los más difíciles es el de la delincuencia, que alcanza el listado de infracciones que temporalmente se han señalado como punibles, las decisiones normativas y de políticas públicas para enfrentarlo, pero también porque en su definición y tratamiento se desenvuelven las visiones de sociedad, sus oposiciones, uso de los bienes y designación de lo humano que de cada parte tienen. Recaen sobre la delgada línea que separa decisionismo de estado de derecho, poder y derechos.

La cuestión delincuencial se vuelve así un espacio tanto de debate como de disputa acerca del modo construir una sociedad, de los límites de lo declaradamente lícito y de aquello que se tolera de facto, un sistema

Facultad de Derecho y Ciencias Sociales - Universidad de Valparaíso - Chile 
de penalidades funcionales a los intereses que sostienen las diversas formas organizativas de lo social. "Las dos principales funcionalidades del sistema de penalidades, entonces, logran consustanciarse en la docilización de los cuerpos y en la producción de delincuencia, permitiendo por parte de las dinámicas de poder y dominación social la extracción de líneas estratégicas, sea por que la docilización de los cuerpos se dirige también a la utilización económica de las fuerzas corporales (la domesticación del delincuente en trabajador), sea porque la producción de la delincuencia contribuye para la moralización de la clase trabajadora y para el ocultamiento de la criminalidad que pueda asociarse a la clase dominante" ${ }^{1}$.

Al hablar de delincuencia estamos también hablando de otras cuestiones socialmente determinantes en el corto y largo plazo: pobreza, las formas de comprenderla, del lugar social del trabajo, de políticas públicas y su sentido, acerca del tipo de inversión social, como del modelo de Estado a construir. Por eso atender a las hablas, a lo que se piensa y dice sobre delincuencia deviene en una cuestión central. Como sostiene Judith Butler, aludiendo a Monique Wittig, "el lenguaje es una serie de actos, repetidos a lo largo del tiempo, que crean efectos de realidad que a veces se consideran erróneamente como «hechos»" ${ }^{2}$ y entonces ya no sólo describe sino que crea realidad.

El presente trabajo pretende exponer los discursos que sobre la cuestión delincuencial se producen en Chile, aquellos que copan el espacio público de lo que se dice, que buscan construir una hegemonía

1. CHIES, Luiz Antonio: A questao penitenciária. En Tempo Social. Revista de sociología da Universidad de Sao Paulo. Volumen 25, N 1. 2013. Págs. 22-

23. En el original: As duas principais funções do sistema de sanções, e, em seguida, o alcançado consustanciarse docilizacion do corpo e na produção do crime, permitindo que a parte da dinâmica de poder e dominação social a remoção de linhas estratégicas, quer pela docilizacion dos organismos também são direcionadas para o aproveitamento econômico das forças corporais (a domesticação dos infratores do trabalhador), é porque a produção do crime contribui para a moralização da classe operária, e a ocultação de crimes que podem estar associados com a classe dirigente.

2. BUTLER, Judith. El Género en disputa. Feminismo y la subversión de la identidad. Ediciones Paidós Ibérica S.A. Barcelona. 2007. Pág. 231.

Revista de Ciencias Sociales - Número 63 (2013) - Universidad de Valparáíso - ISSN 0716-7725-Valparaíso, Chile 
de mirada en la producción de las políticas normativas y sociales, como también en las decisiones de inversión económica públicas y privadas que para enfrentar la delincuencia se realizan. Analizaremos los principales exponentes de discursos que sobre la materia circulan en Chile, tanto aquellos que provienen de organizaciones civiles activas, mayoritariamente de sesgo conservador, los informes de derechos humanos y de derechos como los discursos políticos más visibles.

\section{Describiendo discursos}

De acuerdo con el análisis topológico que realizaremos, dividiremos a los emisores en los siguientes grupos:

\section{a) Conservadores peligrosistas}

El centro especializado del sector en Chile es, sin duda, la Fundación Paz Ciudadana ${ }^{3}$. Formada en 1992 es presidida desde entonces por el presidente del diario El Mercurio Agustín Edwards y suma académicos y políticos de derecha primero y personeros de la centro izquierda más tarde. Declara financiamiento de los principales bancos y grupos empresariales chilenos. Emite opiniones, estudios y encuestas sobre seguridad pública siguiendo las doctrinas norteamericanas sobre seguridad social. En su memoria 2012 señala que "como país hemos ido superando la discusión politizada sobre las soluciones de la delincuencia. La "visión de sistema”, acuñada por la Fundación, hizo patente la complementariedad entre las áreas de control, prevención y la rehabilitación" y así es que actúa "procurando siempre mantener el criterio de excelencia por sobre consideraciones políticas o ideológicas" ${ }^{5}$.

3. www.pazciudadana.cl Todas las fuentes, opiniones e informes que se mencionan de la mencionada Fundación Paz Ciudadana, pueden ser descargadas desde esta página web.

4. FUNDACIÓN PAZ CIUDADANA: Memoria 2012. Santiago. 2013. Pág. 7.

5. Ídem. Pág. 9.

Facultad de Derecho y Ciencias Sociales - Universidad de Valparaíso - Chile 
Su perspectiva puede apreciarse por ejemplo en la Revista Conceptos, que en su número de 29 de Marzo de 2013 presentó el modelo "Communities That Care" (CTC) es un sistema de planificación, ejecución y gestión del trabajo a nivel de barrios o comunidades en materia de prevención social, desarrollado por los investigadores J. David Hawkins y Richard F. Catalano del Grupo de Investigación sobre el Desarrollo Social (Social Development Research Group, SDRG) de la Universidad de Washington"6; que pretende una comprensión del comportamiento humano revisando los elementos que lo determinan por medio de la influencia de personas o entornos sociales significativos para el individuo. Para éste modelo las influencias y los estímulos premio/ recompensa resultan determinantes para el actuar de los niños y niñas y la transmisión de modelos correctos de comportamiento, aquellos que se adhieren al orden social versus los comportamientos incorrectos o desviados de ese orden. Así “el diseño del plan de acción que se encuentra fundamentado en la Estrategia de Desarrollo Social, la que propone instalar o fortalecer dispositivos o programas en la comunidad para los aspectos diagnosticados como deficitarios" , aplicando actividades que no incluyan las de carácter antisocial y que lleven a premios por ello, mediante un sistema de premio castigo focalizado.

Además trabaja con estudios de opinión pública organizados sobre los conceptos de percepción y victimización. Se cruzan los datos de delincuencia objetiva por delitos cometidos en hogares con la percepción subjetiva de sentirse víctimas de la delincuencia. Elabora anualmente una encuesta de victimización, que contiene conclusiones por subtema tratado y no un balance general, de manera que no es posible encontrar un análisis completo y profundo de delincuencia sino un énfasis en la sensación de seguridad ${ }^{8}$. Por ejemplo, el Índice de Junio

6. FUNDACIÓN PAZ CIUDADANA: Conceptos. Marzo de 2013. Santiago. Pág. 1.

7. Ídem. Pág. 9.

8. FUNDACIÓN PAZ CIUDADANA: Balance de la delincuencia 2012. Mayo de 2013. Santiago. 2013.

Revista de Ciencias Sociales - Número 63 (2013) - Universidad de Valparáíso - ISSN 0716-7725-Valparaíso, Chile 
de 2013 indica que en Santiago ha aumentado el índice de victimización en un $1 \%$, aumentando los niveles de "percepción" y temor de la delincuencia a la par que mantienen sus niveles de aprobación las instituciones, lo que no necesariamente es consistente. Para el año 2013, al reponer el tema de la percepción, en año de elecciones presidenciales, repone el tema de la victimización en el debate político.

Propone además construcción de "La Tercera Generación De Políticas Públicas De Seguridad Que Chile Necesita" señalando que si una primera generación de políticas nace el año 2000 con la creación de un programa presupuestario de la Subsecretaría del Interior para el Programa Comuna Segura, que posteriormente "lideró la publicación de la Política Nacional de Seguridad Ciudadana de 2004 y la Estrategia Nacional de Seguridad Pública de 2006", una segunda generación sintetizada en la Estrategia de Seguridad Pública Plan Chile Seguro 2010-2014 obliga a plantearse una tercera generación dado "que la suma de miles de problemas delictivos a lo largo del país, y no ocurre al azar. Es predecible y, por lo tanto, prevenible. Tampoco es cierto que, como se suponía por largo tiempo, el actuar focalizado en algún lugar implicaba el mero desplazamiento de los delitos. Todo esto implica que si bien la reacción ante la ocurrencia de delitos es importante, por sí sola no aporta lo suficiente para evitar que se vuelvan a repetir" ${ }^{\prime 0}$.

Se trata de conseguir un Estado más eficaz trabajando en las áreas de prevención temprana, promoviendo el trabajo con "las familias de todos los menores con alto perfil de riesgo delictivo... para reducir conductas de riesgo y lograr sendas de desarrollo positivas (terapia multisistémica)" 11 ; de incorporar elementos de seguridad en bienes y locales comerciales, dotar a las viviendas con estándares de seguridad mínimos que deberán certificarse; de enfrentar dos grandes la distribución y venta de bienes robados y la violencia con armas de fuego

9. FUNDACIÓN PAZ CIUDADANA: La Tercera Generación de Políticas Públicas y de Seguridad que Chile necesita. Septiembre 2013.Santiago. Pág. 1.

10. Ídem. Pág. 1.

11. Ibídem. Pág. 6.

Facultad de Derecho y Ciencias Sociales - Universidad de Valparaíso - Chile 
en barrios críticos. Además indica deberán realizarse programas de reinserción de mejor calidad, tratamientos para la adicción a drogas, programas de inserción laboral y rediseñar la oferta post penitenciaria, además de reformas legales especializando la justicia juvenil, un nuevo sistema de ejecución penal, servicios administrativos nuevos y mejor planeamiento urbano.

"Chile gasta relativamente poco en seguridad pública en relación a EE.UU. y Europa (Olavarría y Contreras 2005), pero además gasta mal: cuando mucho, el $10 \%$ del presupuesto en seguridad pública en Chile hoy se destina a prevención social del delito, en circunstancias que la evidencia indica que tiene mayores beneficios y menores costos para la sociedad en su conjunto" ${ }^{12}$. Existe así necesidad de reordenamiento administrativo, construcción de indicadores de eficacia, registros de prófugos y flujos en la justicia penal, modelos de gestión basados en resultados, bonos por resultados; desconcentración del trabajo hacia los gobiernos regionales, que el Ministerio Público publique "indicadores de eficiencia, de eficacia y de resultado, por tipo de delito ingresado y fiscalía"13; y capacitación conjunta para fiscales y policías.

En materia de cárceles trata de las concesionadas a privados, que describe como más caro que las operadas por el sector público. En el Informe denominado "Evaluación del sistema concesionado versus el sistema tradicional en la reducción de la reincidencia delictual", en conjunto con el Banco Interamericano de Desarrollo ${ }^{14}$ señala que buscando "proveer evidencia acerca de si las cárceles concesionadas son más efectivas que las cárceles operadas por el Estado en términos de uno de los indicadores de desempeño (performance) del sistema penitenciario: la reincidencia" ${ }^{15}$, estudiando la asignación de presos a

12. Ibídem. Pág. 14.

13. Ibídem. Pág. 17.

14. FUNDACIÓN PAZ CIUDADANA, BANCO INTERAMERICANO DE DESARROLLO: Evaluación del sistema concesionado versus el sistema tradicional en la reducción de la reincidencia delictual. Junio 2013. Santiago. 2013.

15. Ídem. Pág. 143.

Revista de Ciencias Sociales - Número 63 (2013) - Universidad de Valparáíso - ISSN 0716-7725-Valparáiso, Chile 
un tipo y otra de cárceles, beneficios que se conceden y sanciones aplicadas concluye que "de acuerdo a las entrevistas realizadas a diferentes operadores, la Ley de Concesiones sería un marco regulatorio que no parece ajustarse a las realidades de la operación en materia penitenciaria. En particular, no otorgaría la flexibilidad que requiere la operación en estas áreas, sujeta intrínsecamente a cambios constantes, en términos de la composición de la población penal y las necesidades de los internos, entre otras. En la práctica, esto provocaría que los gobiernos se encuentren, de cierta forma, cooptados con una oferta que puede no ajustarse a la realidad existente durante todo el periodo concesión. Esto, sin duda, se contrapone con el argumento de la flexibilidad que usualmente es invocado por la experiencia internacional para justificar la introducción del capital privado en el sistema penitenciario" ${ }^{\prime 16}$. Analizado ya desde el punto de vista de costo y beneficio "el gasto promedio por interno mensual en el sistema operado por el Estado alcanzó una cifra de US $\$ 676,73$, importe menor a los US $\$ 886,4530$ que se exhibe en el Grupo 3 del sistema concesionado. Por eso, junto con la necesidad de llevar a cabo nuevas evaluaciones de impacto que permitan testear el desempeño del modelo concesionado en los Grupos 2 y 3, resulta preciso realizar ejercicios rigurosos de análisis costo-beneficio que permitan evaluar la conveniencia de mantener la participación del mundo privado en la operación de recintos penitenciarios" 17 .

Se trata de una visión de la criminalidad neo conductista, con orientación a la eficacia económica, a un modelo de estado en base a proyectos de eficiencia y distribución de premios por gestión y que propone incidir por vía indirecta en el órgano autónomo del Ministerio Público mediante la capacitación conjunta de Fiscales y Policías orientada a la eficiencia numérica y no a una ratio jurídica profunda. Las mejoras en estándares de certificación e implementos de seguridad en casas y comercio, que deben ser comprados por cierto, atienden a una lógica de mercado.

\footnotetext{
16. Ibídem. Pág. 147.

17. Ibídem. Pág. 149.
}

Facultad de Derecho y Ciencias Sociales - Universidad de Valparaíso - Chile 
El segundo gran generador de pensamiento es el Instituto Libertad y Desarrollo ${ }^{18}$, creado en 1990 para promover la libertad individual, el libre funcionamiento de los mercados, el derecho de propiedad y el progreso e igualdad de oportunidades entre sus habitantes a través del desarrollo económico, incidiendo en la investigación y formación de políticas públicas. Mantiene programas de investigación en las siguientes áreas: Económico y social, seguridad pública y justicia, sociedad política y legislativo. En concordancia con Paz Ciudadana trabaja con los conceptos de victimización y percepción sobre la delincuencia.

En su boletín Temas Públicos, de Marzo de 2013, refiere sobre la baja en la victimización general producto de los esfuerzos del gobierno basados en el Programa Chile Seguro 2010-2014. Señala como “desafíos relevantes en evaluación de programas, aumento de indicadores de rendición de cuentas de las instituciones, mayor énfasis en la prevención secundaria y terciaria, y descentralización" ${ }^{19}$ para continuar en esa senda. Comenta la encuesta de Paz Ciudadana y Adimark, como el instrumento más importante para conocer sobre victimización en el país y concluye que "Los resultados presentados para el segundo semestre de 2012 son positivos, sobre todo en términos de victimización, puesto que además de mostrar una reducción importante de ésta, rompen la tendencia al alza que se venía presentando desde fines de $2010^{\prime 20}$ y que al buen trabajo del gobierno debe agregarse en el futuro "los perfeccionamientos de la Reforma Procesal Penal, que apuntan a mejorar la coordinación entre policías y fiscales y mejorar su capacitación. Otro punto relevante está en aumentar la rendición de cuentas de los diversos actores del sistema de manera de lograr un trabajo más eficiente y eficaz de los recursos utilizados por parte del Estado y lograr avances sólidos en la reducción del delito. En este punto es

\footnotetext{
18. www.lyd.com

19. LiBERTAD Y DESARROLlO. Temas Públicos. No 1.10328 de marzo de 2011. Santiago. Pág. 3.

20. LiBERTAD Y DESARROLLO. Temas Públicos. No 1.09718 de enero de 2013. Santiago. Pág. 4.
}

Revista de Ciencias Sociales - Número 63 (2013) - Universidad de Valparáíso - ISSN 0716-7725-Valparaíso, Chile 
importante aumentar la rendición de cuentas y mecanismos de evaluación de desempeño tanto de jueces, fiscales y policías”21.

En materias de reforma al sistema Procesal Penal señala que de los informes no públicos (¿cómo tiene acceso a ellos?) pueden valorarse las siguientes propuestas:

- "la escasa coordinación existente entre los fiscales y las policías, tanto en términos de información —-sumamente relevante a la hora de proponer y evaluar estrategias de persecución criminal - como en cuestiones más prácticas respecto a las primeras diligencias investigativas frente a la comisión de un determinado delito, y en donde se juega, en definitiva, la capacidad del sistema de dar respuestas a las víctimas. La falta de coordinación es una de las ineficiencias y problemas prácticos que contribuyen en gran medida a generar franjas de impunidad y explican por qué un fiscal terminará archivando un caso haciendo uso de sus facultades discrecionales" 22 .

- Pone énfasis en la labor del trabajo policía destacando la propuesta tendiente a facultar a los funcionarios policiales a que tomen conocimiento de un hecho con características de delito, para que puedan identificar testigos y consignar sus declaraciones, aun no tratándose de un delito flagrante.

- Valora otras medidas como: (i) ampliar la procedencia del recurso de apelación en distintas hipótesis de exclusión de prueba, a favor de fiscales y defensores; (ii) restringir las consecuencias por no presentación de la acusación del Ministerio Público dentro de plazo; (iii) eliminar el que la ausencia del fiscal o su abogado asistente a la audiencia de control de detención importe la liberación del detenido, al menos en delitos que tengan asociada pena de crimen; y (iv)

21. Ídem. Pág. 5.

22. LIBERTAD Y DESARROLLO. Temas Públicos. No 1.08816 de noviembre de 2012. Santiago. Pág. 2.

Facultad de Derecho y Ciencias Sociales - Universidad de Valparaíso - Chile 
limitar el otorgamiento de la suspensión condicional del procedimiento a imputados habituales. Rescatar las medidas tendientes realizar "modificaciones legislativas, tendientes a generar mecanismos inteligentes de control a la discrecionalidad de los fiscales, fue una cuestión constante en el debate de la Comisión"²3.

- Para Justicia adolescente una reforma asociada a disminuir las brechas de impunidad y potenciar los programas de reinserción que "deben ir acompañados, por supuesto, por políticas de prevención centradas en cortar carreras criminales a temprana edad" ${ }^{24}$, aumentando las sanciones toda vez que "un caso emblemático es la existencia, y gran uso, de las amonestaciones, sanción cuyo impacto es menor y en la práctica irrelevante desde la perspectiva de alterar conductas de los jóvenes. Asimismo, la aplicación de sanciones alternativas por parte de los jueces suelen tener poca efectividad y muchas veces con una supervisión inexistente, que no conducen a los objetivos que se persiguen: corregir comportamientos, rehabilitación y reinserción. En esta materia también conviene revisar la suspensión condicional del procedimiento, por cuanto su aplicación indiscriminada y el mal uso de ella que se ha hecho, fomenta precisamente la sensación de impunidad que se pretende evitar" ${ }^{25}$.

En Noviembre de 2012 emitió un informe denominado "Cárceles Concesionadas. Revitalizando el Modelo"26, fruto de un seminario sobre la materia en que "Libertad y Desarrollo quiso volver a poner sobre la

\footnotetext{
23. Ídem. Pág. 4.

24. LiBERTAD Y DESARROLLO. Temas Públicos. No 1.10512 de abril de 2013. Pág. 10.

25. Ídem. Pág. 11.

26. LIBERTAD Y DESARROLLO. Cárceles Concesionadas. Revitalizando el Modelo. Santiago. 2012.
}

Revista de Ciencias Sociales - Número 63 (2013) - Universidad de Valparáíso - ISSN 0716-7725-Valparaíso, Chile 
mesa el modelo de concesiones penitenciarias, como una opción válida, atractiva y necesaria en nuestro país" ${ }^{27}$ incorporando las flexibilidades necesarias y el perfeccionamiento de los contratos para el aprovechamiento de las capacidades del sector privado en términos de competencia, creatividad, innovación y tecnología para los actuales y futuros penales. Hace una reseña del sistema de cárceles concesionadas, presenta un informe del entonces Ministro de Justica, la exposición del experto Inglés Ian Blakeman, del Jefe de División de Explotación de Obras Concesionadas, Ministerio de Obras Públicas, del Gerente de Estudios, Cámara Chilena de la Construcción y del Director de Justice Services, $\mathrm{SODEXO}^{28}$, quienes llaman a profundizar el modelo y generar flexibilidades para ello; opiniones que contradicen el estudio de Paz Ciudadana y el Banco Interamericano de desarrollo que más bien alertan sobre la eficacia y eficiencia de estas inversiones.

Finalmente el Centro de Estudios Públicos CEP, fundado en 1980 contribuye al debate divulgando opiniones sobre la materia. Específicamente encontramos en su web un estudio conjunto del año 2006 con la Pontificia Universidad Católica de Chile denominado "Camino al Bicentenario" que contiene el artículo "Delincuencia en Chile: determinantes y rol de las políticas públicas", firmado por Harald Beyer y Rodrigo Vergara basado en métodos econométricos, la Teoría del Crimen (Becker, 1968), la idea que la delincuencia está asociada a una teoría de la utilidad esperada al delinquir de costo beneficio y explicaciones neurobiológicas no justificadas sobre la persona del delincuente. "El género de la persona es quizás el mejor predictor del crimen. En todas las sociedades donde existen registros la prevalencia de delitos es mayor entre los hombres. (Wilson y Herrnstein. 1985)"29 y mayor entre los adolescentes que en adultos. Otros factores sociales que inciden en el delito, entre ellos "la calidad de los padres" ${ }^{30}$, con mujeres

27. Ídem. Pág. 5.

28. Empresa que recibió la concesión de cárceles en Chile y que también administra los recursos de becas de alimentos para estudiantes en el país.

29. BEYER, Harald y VERGARA, Rodrigo: Delincuencia en Chile: determinantes y rol de las políticas públicas. Pontificia Universidad Católica de Chile. 2006. Pág. 19.

30. Ídem. Pág. 20.

Facultad de Derecho y Ciencias Sociales - Universidad de Valparaíso - Chile 
como jefe de hogar y consumo de drogas. A partir de las investigaciones de Becker y Ehrlich establecen que los delincuentes son racionales que analizan al momento de delinquir los sistemas de costo beneficio de su accionar, de manera que la probabilidad de ir a la cárcel es uno de ellos. La efectividad de la policía y de Tribunales para condenar sería un factor en consecuencia. "En este sentido es preocupante que en nuestro país jueces, fiscales y policías no tengan mayor "responsabilidad política" frente a la población. Parece indispensable, entonces, introducir en algún grado, una mayor rendición de cuentas frente a la comunidad"31.

Desempleo, pobreza y desigualdad se describen como causas, y la mayor educación en el largo plazo una forma de desincentivo. "Hay, entonces, espacio para poner en la política pública el desarrollo de las habilidades no cognitivas - perseverancia, motivación, autocontrol y autoestima- entre otras. Desde el punto de vista de las políticas públicas tanto estas habilidades como las cognitivas pueden ser afectadas por la política pública cuando ellas son afectadas por entornos familiares adversos (éstos influyen en ambos tipos de habilidades). Con todo, las cognitivas requieren de estímulos tempranos mientras que intervenciones más tardías que han intentando influir en el desarrollo de habilidades no cognitivas han demostrado un grado de éxito no despreciable. Las neurociencias parecen dar una respuesta a esta evidencia y dice relación con la maleabilidad de la corteza pre frontal hasta alrededor de los 20 años"32, para lo que sugieren crear hábitos, creencia sociales y promover el trabajo flexibilizando el salario mínimo de los jóvenes.

b) Institucionalistas, que corresponde a opiniones de órganos del Estado para una adecuación de los funcionamientos a un régimen respetuoso de la legalidad y los derechos humanos

La Defensoría Penal Pública, en 2011, mediante su titular Paula Vial, señalaba la necesidad de regular de mejor forma la ejecución de la

\footnotetext{
31. Ibídem. Pág. 43.

32. Ibídem. Pág. 36.
}

Revista de Ciencias Sociales - Número 63 (2013) - Universidad de Valparáíso - ISSN 0716-7725-Valparaíso, Chile 
pena: "En nuestro país, a diferencia de lo que sucede en otros, la ejecución de las penas privativas de libertad ha estado siempre regulada sólo en un reglamento y no en una ley. Existe entonces una abierta infracción al principio de legalidad. Ello implica la vulneración de una serie de garantías constitucionales. Así, se infringe la garantía de la inviolabilidad de las comunicaciones privadas todos los días en cada establecimiento penal, cuando se abre y lee toda la correspondencia que envía y recibe el recluso, por cuanto el reglamento penitenciario lo permite en razón de la seguridad del establecimiento. El derecho a la libertad personal y a la garantía de que ésta no puede ser privada, ni restringida también se ve afectada en los establecimientos penales se sanciona cuando a algún interno que ha cometido una falta grave con aislamiento en celda solitaria" ${ }^{33}$. En esa misma línea su actual director Georgy Shubert ha defendido el concepto de un sistema garantista, de otorgar acceso a la defensa para todas las personas, incluso señalando el estado debe permitir que las personas accedan al sistema interamericano de justicia, cosa que hoy queda reducida a dinero para abogado particular o a intervención de $\mathrm{ONGs}^{34}$, la necesidad de visibilizar a las mujeres en el sistema de defensa introduciendo criterios de género en la formación y capacitación de los defensores, defensa especializada a indígenas, necesidad de autonomía institucional y no dependencia del Ministerio de Justicia ${ }^{35}$ y el Proyecto Inocentes para crear conciencia sobre la importancia del principio de inocencia y debido proceso $^{36}$.

33. VIAL, Paula. 14-04-2011. http://www.latercera.com/noticia/nacional/2011/04/ 680-358522-9-defensora-nacional-exige-reformar-el-sistema-de-penas-enchile.shtml (visita 17 de Octubre de 2013).

34. SHUBERT, Georgy. www.latercera.com/noticia/nacional/2013/07/680535059-9-georgy-shubert-defensoria-debe-poder-asistir-a-los-chilenos-encorte.sthml (visita 17 de Octubre de 2013).

35. $\mathrm{Al}$ respecto puede verse la Cuenta Pública del Defensor Público Nacional del año 2012 en la página web oficial de la Defensoría www.dpp.cl

36. Al respecto puede consultarse la página de la Defensoría www.dpp.cl

Facultad de Derecho y Ciencias Sociales - Universidad de Valparaíso - Chile 
Por su parte el Instituto Nacional de Derechos Humanos (INDH) anualmente emite un informe oficial de derechos humanos que incluye un análisis respecto de las personas privadas de libertad y recomendaciones respecto de las políticas de estado ${ }^{37}$ : insta al Poder Ejecutivo a erradicar el hacinamiento, abstenerse del uso de celdas de aislamiento; recomienda eliminar toda regulación que suspende el derecho a voto a personas acusadas de delitos, abrir un debate acerca de la legitimidad de esta medida, la necesidad de modificar el Reglamento de la Ley 18.216, con el objetivo que entre en vigencia la Ley 20.603 sobre alternativas a la privativa de libertad, como a su vez garantizar condiciones laborales y de seguridad e higiene dignas para el personal de Gendarmería y recomienda a este órgano adoptar medidas para el respeto de los derechos fundamentales de los grupos vulnerados al interior de los establecimientos penitenciarios, como es la población LGBTTI.

Finalmente importa destacar el Informe emitido por la Fiscalía de la Excelentísima Corte Suprema de Justicia, suscrito por doña Mónica Maldonado Croquevielle, presentado al Senado en Junio de 2009 elaborado a partir de las visitas anuales a las cárcel y que en su contenido señalaba que ${ }^{38}$ existe consenso entre autoridades y organismos especializados, que en los últimos años se ha agudizado gravemente la situación por la persistencia de graves situaciones en los establecimientos penitenciarios: Hacinamiento, Horario de desencierro y encierro de los internos, Alimentación de los internos, Falta de política y planes de rehabilitación de los internos, y falta de actividades laborales, de capacitación, educación, deportivas, espirituales y recreativas, Deficientes condiciones sanitarias e higiénicas, Aplicación del castigo

37. INSTITUTO NACIONAL DE DERECHOS HUMANOS. INFORME www.indh.cl ANUAL DE DERECHOS HUMANOS 2012. Santiago. 2013. En

38. Párrafos extractados del Informe presentado en virtud de la invitación de la Comisión de Constitución, Legislación, Justicia y Reglamento del Senado de la República, a la sesión a celebrarse el día $1^{\circ}$ de junio de 2009, para considerar los diversos problemas que afectan al funcionamiento del sistema carcelario en nuestro país.

Revista de Ciencias Sociales - Número 63 (2013) - Universidad de Valparáíso - ISSN 0716-7725-Valparáiso, Chile 
de internación en celda solitaria, y condiciones materiales en que se cumple esta sanción, Aislamiento de internos por razones de seguridad y Muertes de internos en los penales. La condición de hacinamiento en los establecimientos penitenciarios no concesionados es generalizada, variando sólo en los porcentajes que representan con respecto a la capacidad del establecimiento. La situación de hacinamiento se ve agravada por el hecho de permanecer los internos encerrados en sus celdas por espacio de aproximadamente 15 horas diarias, en celdas abarrotadas, que por lo general carecen de servicios higiénicos, y de la adecuada ventilación y luz. Gendarmería ha trastocado el sentido de la norma que asegura 8 horas diarias de descanso para los internos, estableciendo 8 a 9 horas diarias de desencierro para la población penal, horario que hace imposible desarrollar las actividades de rehabilitación que exigen la Ley Orgánica de Gendarmería y el Reglamento de Establecimientos Penitenciarios.

Además del hacinamiento, se apreciaron pésimas condiciones de higiene, servicios higiénicos insuficientes, las celdas de castigo siguen constituyendo un trato cruel e indigno que somete a encierro hasta por 10 días en celdas vacías de cualquier mueble, sin catre, colchón, ni frazadas, las que se les entregan en la noche; celdas que habitualmente no cuentan con luz natural ni eléctrica, la que entra por pequeñas celosías, muchas veces sin servicios higiénicos y sometidos a la buena voluntad de los Gendarmes para que sean sacados a hacer sus necesidades biológicas, o directamente provistos de tiestos plásticos para este fin; y sin acceso a lectura, que es aplicada como sanción administrativa sin recabar previamente la autorización del Juez del lugar para repetir esta medida.

En el caso de las cárceles concesionadas, es necesario que Gendarmería evalúe a través del Inspector Fiscal, el cumplimiento de los servicios penitenciarios que ofrecen las empresas concesionarias, en lo que se refiere a la oferta de trabajo, talleres laborales y maquinarias, capacitación, que se aprecian reducidas en relación con el número de la población, lo que se puede constatar en los Informes de Visitas a dichos establecimientos.

Concluye que en opinión de la Señora Fiscal Judicial, en Chile existe el marco legal y reglamentario suficiente para que el Estado

Facultad de Derecho y Ciencias Sociales - Universidad de Valparaíso - Chile 
cumpla con su deber de velar por la rehabilitación y reinserción social de los reclusos y respetar su dignidad, por lo que la solución de la problemática carcelaria que se arrastra en el tiempo, no pasa por la dictación de nuevas normas legales, sino por la voluntad de las autoridades del sector de implementar políticas penitenciarias, concretar las acciones que se planifiquen, y evaluar sus resultados. Con excepción de las limitaciones propias del encarcelamiento, todos los reclusos siguen gozando de los derechos humanos y las libertades fundamentales consagrados en la Declaración Universal de Derechos Humanos; en el Pacto Internacional de Derechos Económicos, Sociales y Culturales; y el Pacto Internacional de Derechos Civiles y Políticos, normas incorporadas a la legislación nacional. Es obligación del Estado crear las condiciones necesarias para la reincorporación del recluso en la sociedad, y en las mejores condiciones posibles, de modo de disminuir los actuales índices de criminalidad y reincidencia, contribuyendo así al bien común de toda la sociedad.

\section{c) Discursos relacionales y garantistas}

En primer lugar señalaremos al Centro de Derechos Humanos de la Universidad Diego Portales, que anualmente emite un Informe anual de Derechos Humanos ${ }^{39}$, que para el año 2012 en lo medular señala que ${ }^{40}$ :

"El endémico contexto de hacinamiento de las cárceles chilenas constituye en sí mismo una violación a los derechos humanos de los reclusos, y también favorece la violación de otros derechos esenciales, como los de integridad, salud, reinserción, etc. La población penal chilena ha ido en aumento durante las dos últimas décadas: 22.593 reclusos en 1990; 33.131 en 2000; y poco más de 52.000 en 2012. Esta

39. http://www.derechoshumanos.udp.cl/informe-anual-2012/ (visita 18 de Octubre de 2013).

40. Las citas que a continuación se extraen corresponden todas en específico al capítulo del informe denominado Política Criminal y Derechos Humanos. http://www.derechoshumanos.udp.cl/wp-content/uploads/2012/11/7-politicacriminal-y-derechos-humanos.pdf (Visita 18 de Octubre de 2013).

Revista de Ciencias Sociales - Número 63 (2013) - Universidad de Valparáíso - ISSN 0716-7725-Valparaíso, Chile 
cifra se mantiene estable a junio de 2012, cuando la población penal, de acuerdo a cifras de Gendarmería, asciende a 52.612 personas". Pese a ese diagnóstico lapidario el Estado no ha tomado una definición seria y concreta para reducir los niveles de encierro de manera eficaz. Falta una política criminal eficaz en la materia.

De los antecedentes recabados se desprende de manera clara que el sistema selecciona sistemáticamente a los sectores más vulnerables de la población, que poseen menos instrucción y recursos, y además lo hace desde etapas tempranas del desarrollo del individuo. El Estado ha determinado que los delitos de mayor connotación social son los hurtos, robos con fuerza, robos por sorpresa, robos con violencia o intimidación, lesiones, violación y homicidio; categorización que no se fundamenta en un sustrato teórico o criminológico sino que corresponde a una decisión política. Esta decisión es relevante porque determina los delitos que ocupan la mayor atención de parte del gobierno en orden a medir su frecuencia, su referencia geográfica, etc., convirtiéndolos en objeto prioritario de estudio e inversión de recursos. Asimismo, se va fijando una cierta imagen de lo que constituye lo "peligroso" y "la delincuencia" frente a la ciudadanía y a los agentes de persecución penal. A propósito del llamado Escándalo La Polar, estafa masiva a miles de personas por una empresa de retail y el trato beneficioso a los ejecutivos por la justicia señala que "Una política criminal orientada al cumplimiento de las exigencias impuestas por el sistema de derechos humanos exige utilizar el sistema penal como último recurso y la privación de libertad como última ratio. Por ello, lo que se propone aquí no es "mano dura" con los delitos económicos o de "cuello blanco" en general, para impulsar una regulación y trato más igualitario. Por el contrario, si bien se demanda ese trato igualitario para quienes cometen delitos de envergadura equiparable en términos de afección a bienes jurídicos, ese trato, creemos, no debe orientarse a una política de derecho penal “máximo" ${ }^{41}$. Lo que se requiere es rediseñar una política criminal que sea capaz de responder frente a todo tipo de criminalidad, incluida la criminalidad de cuello blanco, de manera igualitaria y digna.

41. Ídem. Pág. 214.

Facultad de Derecho y Ciencias Sociales - Universidad de Valparaíso - Chile 
Los niños y adolescentes que perseguidos por el sistema penal presentan las mismas características de marginalidad de la población adulta expuestas con anterioridad. Por ello, un sistema no especializado es, en la práctica, un sistema doblemente discriminador en contra de los niños y adolescentes: al seleccionarlos por su marginalidad y tratarlos sin la especialización requerida en vista a su etapa de desarrollo.

La Red de Acción Virtual Local Solidarity ${ }^{42}$, a través de su página web informa para el año 2012 que "miradas las cosas con una perspectiva amplia, sostenemos que el problema no se resolverá aumentando las medidas de protección. Creemos que la solución más larga, pero la única eficaz, es apuntar nuestros esfuerzos a que disminuya la gente que hace del delito su medio de vida" ${ }^{43}$. Si por una parte hay más delitos, son más violentos, son cometidos por los más jóvenes, ha aumentado el delito femenino, está más presente la droga y el alcohol, se ha extendido la comisión de delitos por el territorio; todo lo que ha llevado a una extensión del temor. Adjuntan además algunas causales que explican este cuadro: en primer lugar somos un país que persigue los delitos y a la vez existe una mejora real en los índices de delincuencia, se han reformulado leyes y programas, se ha invertido fuertemente en seguridad y además estamos ante una sociedad con alta conciencia sobre el problema. Este incremento es necesario analizarlo también en la persona del delincuente excluyendo los delitos de cuello y corbata ${ }^{44}$. De ésta forma "las investigaciones han demostrado con certeza que las circunstancias tienen mucho que ver en la hechura de un delincuente. Decíamos al comienzo que más exacto y más útil para los efectos de trabajar con el delincuente es considerarlo tan victimario como víctima" $^{45}$. El $89 \%$ pertenece a los sectores más pobres de la sociedad,

42. www.risolidaria.cl Informe 2012. (visita 17 de Octubre de 2013).

43. Ídem. Pág. 56.

44. "No consideramos en esta descripción al delincuente de cuello y corbata que, cabe reconocer, con frecuencia causa más daño a la sociedad que el otro. Nos abocamos al delincuente común porque sospechamos que éste, a diferencia del de "guante blanco", es en la mayoría de los casos producto de las circunstancias adversas que padeció”. Ibídem. Pág. 56.

45. Ibídem. Pág. 62.

Revista de Ciencias Sociales - Número 63 (2013) - Universidad de Valparáíso - ISSN 0716-7725-Valparaíso, Chile 
jóvenes de 15 a 29 años, de mayoría solteros y con hijos, de manera que hay elementos que explican la delincuencia: el desempleo en los jóvenes siempre es mayor que en los adultos lo que genera un deambular por tiempo libre, se suman a esto deserción escolar, desigualdades, familias disfuncionales que inciden en la personalidad.

Respecto de la prisión, "La cárcel no se trata sólo de perder la libertad: es la promiscua convivencia con un conjunto humano que ciertamente no se ha elegido; es el paso del tiempo sin nada que hacer. Es un limbo que no cuenta para la vida personal. Cuando ingenuamente a los presos se les pregunta si acaso se han rehabilitado de su delito, no saben qué contestar" ${ }^{\prime 6}$, el ex convicto habrá estado mucho tiempo fuera de su ambiente como para poder conseguir un trabajo. Este desarraigo de su medio es lo que se llama la "desocialización" del recluso ${ }^{47}$. La reclusión tensiona fuertemente a la familia, hay un tema de prestigio, "de enlodar el apellido". En la medida que el encierro se prolonga, el vínculo afectivo puede debilitarse y el familiar libre puede cambiar de pareja y abandonar al recluso.

Para el trabajo concreto con los condenados el trabajo directo con las personas que las organizaciones de la sociedad civil pueden cumplir resulta vital al no estar condicionada a los ciclos de Gobierno ni a premisas ideológicas que a veces opacan una acción más directa y eficaz. "Una solución intermedia entre la impunidad y la reclusión es el Sistema de Penas Alternativas. Pero una de las dificultades que tiene su aplicación es que no hay suficientes organizaciones sociales que puedan hacerse cargo de los trabajos comunitarios que debe cumplir el reo como alternativa a la cárcel. Por esta razón, la participación de la comunidad es necesaria si queremos que las penas alternativas sean efectivas" $" 8$

CLADEM $^{49}$, Comité de América Latina y el Caribe para la Defensa de los Derechos de la Mujer, ha emitido hace pocos años un

46. Ibídem. Pág. 67.

47. Ibídem. Pág. 70.

48. Ibídem. Pág. 73.

49. CLADEM. www.cladem.org (visita 18 de Octubre de 2013).

Facultad de Derecho y Ciencias Sociales - Universidad de Valparaíso - Chile 
informe sobre prisión femenina en Chile con consideraciones hasta el 2006 que resulta importante en tanto no se encuentran otros estudios disponibles sobre mujeres encarceladas en Chile.

Destacan que la información con que Gendarmería de Chile cuenta para entregar al público en forma inmediata es mínima, el resto no se entrega al público, ya que incluso ha debido en el pasado, antes de la actual ley de transparencia 20.285 de 20 de Agosto de 2008, recurrirse a Tribunales para el acceso a ella por investigadores interesados en el tema. Respecto de las cárceles concesionadas agrega que se presentan problemas con los términos y condiciones de los contratos de concesión; existen demoras en las entregas, incumplimientos de plazos y que respecto de su costo éste no sería más barato que el antiguo, que existe escasa información ya que ni gobierno ni privado las entregan en cuento a financiamiento o litigios, que en los informes no se contiene necesidades específicas respecto de mujeres encarceladas. Una cultura de la no información.

Se denuncian vulneraciones y tratos denigrantes específicos para las mujeres presas como que se encuentran privadas de ejercer la maternidad al quedar separadas de sus hijos, "la atención médica es inadecuada, no hay espacios suficientes y apropiados para la atención médica de las embarazadas y lactantes que carecen de dependencias donde puedan efectuarse exámenes ginecológicos y obstétricos" ${ }^{50}$, además de exceso de recetas de tranquilizantes.

Los delitos más cometidos por las mujeres son los asociados al tráfico de drogas que "se encuentra asociado fundamentalmente a mujeres en extrema pobreza, Jefes de Hogar con hijos y ancianas que consideran el tráfico como un pequeño comercio que les permite sobrevivir" "51; en el caso de la delincuencia rural femenina está muy asociada a delitos de sangre derivados de años de maltratos, a abortos asociados al rechazo social del medio: "La Injusticia radica justamente en el hecho que estas mujeres, después de sufrir entre 10 a 20 años malos tratos físicos y psicológicos, es decir de ser víctimas del machismo

\footnotetext{
50. Ídem. Pág. 9.

51. Ibídem. Pág. 11.
}

Revista de Ciencias Sociales - Número 63 (2013) - Universidad de Valparáíso - ISSN 0716-7725-Valparaíso, Chile 
y el patriarcalismo, y dando muerte a su pareja en una situación de violencia extrema intentando salvar sus vidas o las de sus hijos, son condenadas por otros 10 a 20 años de cárcel, lo que implica no sólo un sufrimiento adicional para ellas, sino también para sus hijos. Las mujeres víctimas de malos tratos, es decir, víctimas del tradicional Conflicto Intrafamiliar, se encuentran cumpliendo condena cubiertas de tajos, con huesos mal soldados, quemadas, con cicatrices de balazos o cuchilladas, todas lesiones efectuadas por sus parejas masculinas" 52 .

La relación con Gendarmería es también un problema que se une a las paupérrimas condiciones de trabajo de la guardia de prisiones, que incide en el trato entre ellos mismos y las condiciones de arbitrariedad que llegan hasta los/as reclusos/as. Lo que se extiende a familiares y terceros. Por ejemplo, las mujeres que acuden de visita a la cárcel se les efectúan revisiones corporales denigrantes, deben “desvestirse frente a funcionarias de Gendarmería y muchas veces son obligadas a agacharse y son registradas al interior de su cuerpo, en la vagina o el ano" 53 .

\section{d) Los discursos políticos}

Nos parece oportuno revisar además las opiniones de las principales figuras y tendencias políticas en competencia por que permite analizar cuanto de importancia adquiere el tema en la clase política, para lo cual las dividiremos por las candidaturas a la presidencia y sus grupos de apoyo presentes en las elecciones de 2013.

Alianza por Chile. Que corresponde a los partidos de derecha que forman a su vez la base política del gobierno 2010-2014 que coincide con la segunda estrategia nacional antidelincuencia.

De entre sus personeros más importantes, por ejemplo Rodrigo Hinzpeter, quién fue Ministro del Interior y que definió la estrategia

\footnotetext{
52. Ibídem. Pág. 11.

53. HERRERA, Marcela. Informe de Mujeres Privadas de Libertad en Chile. Elaborado por el Grupo de Enlace de CLADEM en Chile Responsable del equipo, Marcela Herrera. Santiago. 2012. Pág. 9.
}

Facultad de Derecho y Ciencias Sociales - Universidad de Valparaíso - Chile 
2010-2014 mencionada, a dos años de gobierno declaraba que "los delincuentes son astutos e inteligentes, además se esconden en el anonimato, muchas veces cometen los delitos de noche, atacan a los más débiles y actúan fuera de la ley ¿Y nosotros qué tenemos que hacer? Actuar a rostro descubierto, a vista de todos y dentro del marco de la ley, por tanto la lucha no es en igualdad de condiciones..." ${ }^{54}$. O el Senador Alberto Espina que expresaba que "Los datos muestran que hay alrededor de $\mathbf{3 0 0}$ mil delitos al año menos que se han cometido. Tengo el dato oficial y dice exactamente que la delincuencia ha disminuido un $21,7 \%$ esto no lo invento yo ni el Gobierno, son datos de una institución de Estado independiente...Pero la realidad de las cosas, cuando uno dice estas cifras, la gente con razón se indigna porque en realidad todavía tenemos altísimos niveles de delincuencia y esa es la verdad, particularmente de los robos con violencia y donde las falencias que hay a mí me dejan super preocupado...( agregando) Siempre he sostenido que una de nuestras principales falencias es no haberle dado más facultades a los carabineros y a las policías” señaló, explicando que —a su juicio— ha existido una negativa de darle más atribuciones a las policías, cuando éstas no son suficientes" ${ }^{\text {. }}$.

La candidata presidencial por ese sector Evelyn Matthei ante el consejo Consultivo de Paz Ciudadana 2013, presentó los cinco ejes para combatir la delincuencia y el narcotráfico de su programa presidencial ${ }^{56}$ :

1. Prevención, en colegios y liceos de Chile, implementando programas de prevención de la violencia escolar y de consumo de drogas.

54. HINZPETER, Rodrigo. A dos Años de Gobierno. Lanacion.cl 24 de enero de 2012, citado por el Informe Anual sobre Derechos Humanos en Chile 2012.

Universidad Diego Portales. Pág. 199. El subrayado es nuestro.

55. ESPINA, Alberto. http://www.lanacion.cl/espina-y-la-delincuencia-se-creouna-expectativa-muy-alta/noticias/2013-08-02/210218.html 2 de agosto de 2013. (visita 18 de Octubre de 2013).

\footnotetext{
56. www.rn.cl/v1/component/k2/item/5982-evelyn-matthei-presento-suspropuestas-de-seguridad-pública-con-énfasis-en-prevencion-y-mano-firme (visita 18 de Octubre de 2013). Los subrayados son nuestros.
}

Revista de Ciencias Sociales - Número 63 (2013) - Universidad de Valparáíso - ISSN 0716-7725-Valparáiso, Chile 
2. Rehabilitación, con un programa de tratamiento de alta complejidad para adolescentes que sufren de consumo problemático de drogas y alcohol.

3. Modernización de las policías. "6.000 nuevos carabineros en las calles, con más atribuciones. Que puedan hacer de inmediato las primeras diligencias de la investigación de un delito. Construiremos 50 nuevas comisarías o retenes y 50 cuarteles de la PDI en zonas geográficas sugeridas por los alcaldes y concejales de las 100 comunas con mayor índice delictual, luego de consultarlas con los respectivos vecinos".

4. Lucha contra el narcotráfico, con herramientas tecnológicas y más recursos humanos para disminuir la internación de drogas. Fiscalización de empresas dedicadas a la importación, exportación, venta, almacenamiento y/o transporte de precursores y sustancias químicas de uso potencial para la fabricación de drogas ilícitas.

5. Poder judicial. "Instauraremos un observatorio judicial, que va a ser un registro público sobre los jueces que existen, en qué tribunales trabajan, qué tipo de causas fallan, a quiénes dejan libres. Este observatorio deberá ser un ente independiente del Gobierno de turno, pero financiado con dineros públicos. Estará monitoreado por abogados, sociólogos e ingenieros, de tal manera que sean públicos, para la ciudadanía y para la prensa, los criterios que usa cada juez", señaló la abanderada.

Nueva Mayoría. Michelle Bachelet, candidata presidencial con fecha 24 de Septiembre en una entrevista dada a Radio Cooperativa presentó sus propuestas antidelicuencia acompañado de un par de expertos de su comando y señalós7: "Sobre las medidas para combatir el delito, propuso aumentar el número de dotación policial a 6.000 nuevos carabineros y 1.200 policías, un plan especial para mil colegios en riesgo social para evitar el consumo de drogas, reformular los planes cuadrantes e incrementar los recursos para el Ministerio Público y cantidad de fiscales que investiguen las causas". La asesora Javiera Blanco, recordó que "la Presidenta en su Gobierno impulsó un proyecto de

57. www.cooperativa.cl Bachelet. No podemos seguir enfrentando el problema con slogans de campaña. 24-09-3013. (visita 18 de Octubre de 2013). El subrayado es nuestro.

Facultad de Derecho y Ciencias Sociales - Universidad de Valparaíso - Chile 
fortalecimiento del Ministerio Público que este Gobierno finalmente no hizo prosperar. Era un proyecto que contemplaba no sólo fortalecimiento en términos de más fiscales sino también la creación de unidades de foco de análisis delictual". Jaime Arellano, ex subsecretario de Justicia sobre sistema penitenciario: "El tema de infraestructura es un tema endémico en el sistema carcelario chileno. Durante los gobiernos de la Concertación se aumentó tremendamente la capacidad y se disminuyó el hacinamiento, pero el sistema de justicia efectiva en materia penal obviamente aumenta la población", expuso. "Lo que hemos propuesto obviamente es revisar los modelos que existen actualmente para infraestructura y evidentemente continuar dotando de capacidad y reduciendo el hacinamiento en las cárceles”, sentenció. En la página web de su candidatura se encuentran 20 medidas en los ítemes de Prevención, Violencia de género, drogas, policía, persecución penal, atención de víctimas, sistema penitenciario y justicia penal adolescente $^{58}$. En materia penitenciaria dicen que aumentarán la oferta programática para reinserción. Para justicia juvenil un programa laboral de reinserción y mayor especialización a todos los órganos.

Marco Enríquez Ominami, candidato del Partido Progresista, en entrevista al periódico The Clinic ${ }^{59}$ de fecha 19 de mayo de 2013 señaló: "los chilenos ya no solamente tienen miedo a que lo asalten, sino que ahora hay miedo a las cifras. Ahora incluso las cifras están en tela de juicio. Estamos en el peor de los mundos, porque una cosa es el miedo a que te asalten y ahora el miedo a que las cifras sean reales. No sabemos si estamos bien o mal". Respecto del combate a las drogas, sostuvo que "tan enfermo como un drogadicto es un Gobierno que trata a los consumidores como delincuentes. Se cuentan por decenas de miles los arrestados y este Gobierno ha endurecido la mano en materia de combate a los consumidores. Pero fue el anterior, el Gobierno de Michelle Bachelet, el que catalogó la marihuana como droga dura y la transformó en lo mismo que la cocaína. Convirtió a los consumidores de marihuana en delincuentes que son tratados con la misma dureza que un gran

58. www.michellebachelet.cl/seguridad/

59. ENRIQUEZ OMINAMI, Marco. www.theclinic.cl 19 de mayo de 2013 (visita 18 de Octubre de 2013).

Revista de Ciencias Sociales - Número 63 (2013) - Universidad de Valparáíso - ISSN 0716-7725-Valparaíso, Chile 
narcotraficante. Consultada su página de campaña ${ }^{60}$ no presenta un listado de ideas específicas sobre la materia. El buscador refiere a presentación ante Paz Ciudadana el 26 de Septiembre de 2013 donde habla de prevención, reducción de segregación urbana y mejoramiento de calidad de vida, creación de una política de rehabilitación y reinserción, mejoramiento del sistema judicial y del Ministerio Público. Respecto de delincuencia cuestionó la ampliación de la ley de drogas, el criterio blando con los delitos blancos o de cuello y corbata, y la necesidad de reestructurar el Servicio Nacional de Menores.

El candidato Ecologista Alfredo Sfeir en la página web de su candidatura, sección programa de gobierno $\mathrm{N}^{\circ} 9$ se refiere al problema de la violencia y propone "Refaccionar los programas de las cárceles de Chile para minimizar la reincidencia y aumentar radicalmente la integración familiar y social. Hacer reuniones con los grupos que aparecen como las fuentes de la violencia y llegar a acuerdos sociales que ataquen las causas y la eliminen progresivamente. Estructurar un nuevo programa de Carabineros de Chile que incluya formas de intervención no violenta, la inserción social y el apoyo comunitario" ${ }^{61}$.

Ricardo Israel, candidato del Partido Regionalista Independiente propone una ley especial para el vandalismo y regulaciones en las medidas alternativas al presidio efectivo. En su página de campaña ${ }^{62}$ dedica un capítulo de su programa a seguridad pública nacional, regional y local y contempla: fortalecer la Subsecretaría de Prevención del Delito, dotar a los gobiernos regionales y locales de capacidad de trabajar el problema, intervenir los espacios públicos, capacitación y reforma policial, creación de nuevas comisarías y Escuadrones de Carabineros por Regiones, mejoramiento de la Ley de Seguridad privada.

Tomás Jocelyn Holt ${ }^{63}$ candidato independiente solo propone despenalización del autocultivo de marihuana, dejar las detenciones

\footnotetext{
60. www.marco2014.cl

61. www.Sfeir2014.cl/programa-presidencial\# page=IX (visita18 de Octubre de 2013).

62. ricardoisraelpresidente2014.blogspot.com.br (visita 18 de Octubre de 2013).

63. www.tomaspresidente.cl/compromiso-de-campana-tomas-2014-plan-joven-ydespenalizacion/ (visita 18 de Octubre de 2013).
}

Facultad de Derecho y Ciencias Sociales - Universidad de Valparaíso - Chile 
por consumo y tenencia, desarrollar una nueva política policial sobre drogas.

Los candidatos Marcel Claude, de izquierda humanista, Roxana Miranda del Partido Igualdad, no presentan propuestas específicas en sus páginas $\mathrm{web}^{64}$. Franco Parisi, independiente no tiene página web ni en prensa aparecen propuestas sobre delincuencia.

\section{Una síntesis topológica}

Esta información nos permite así conocer los principales conceptos utilizados por los sectores que mencionamos, compararlos y dibujar, además de semejanzas y diferencias, una jerarquía topológica, describir las miradas sobre delincuencia, las visiones que fundamentan las decisiones políticas, los valores jurídicos que se juegan en ellas y el tipo hermenéutica que cada sector propone para el debate político y jurídico.

La siguiente tabla grafica los principales tópicos usados por cada actor:

\begin{tabular}{|c|c|}
\hline Emisor & Topois más usados \\
\hline Paz Ciudadana & $\begin{array}{l}\text { Despolitización, Prevención, Premio/Castigo, Percepción, } \\
\text { Victimización, Predicción, Prevención temprana, Riesgo, Seguridad, } \\
\text { Reinserción, Drogas, Costo/beneficio, Gestión, Transparencia, } \\
\text { Capacitación, Reincidencia, Descentralización, Cárcel, Concesión, } \\
\text { Flexibilidad, Ministerio Público, Jueces, Policías, Dotación policial. }\end{array}$ \\
\hline $\begin{array}{l}\text { Libertad y } \\
\text { Desarrollo. }\end{array}$ & $\begin{array}{l}\text { Victimización, Percepción, Descentralización, Prevención, } \\
\text { Eficiencia, Capacitación, Rendición de cuentas, Evaluación de } \\
\text { desempeño, Ministerio Público, Jueces, Policías, Dotación policial, } \\
\text { Impunidad, Medidas de seguridad, Restringir, Limitar, Control de } \\
\text { discrecionalidad, Prevención temprana, Sanciones, Cárcel, } \\
\text { Concesión, Sector privado, Flexibilidad. }\end{array}$ \\
\hline $\begin{array}{l}\text { Centro de Estudios } \\
\text { Públicos. }\end{array}$ & $\begin{array}{l}\text { Costo/beneficio, Género, Calidad Paterna, Drogas, Efectividad, } \\
\text { Condena, Causas, Desincentivo, Factores biológicos, Entorno } \\
\text { familiar adverso, Estímulos tempranos, Neurociencia, Hábitos, } \\
\text { Creencias sociales, Flexibilizar, Policía, Dotación policial, Jueces, } \\
\text { Ministerio Público, Responsabilidad Política, Rendición de cuentas. }\end{array}$ \\
\hline
\end{tabular}

64. www.to2alamoneda.cl y www.roxanamiranda.cl (visita 18 de Octubre de 2013).

Revista de Ciencias Sociales - Número 63 (2013) - Universidad de Valparaíso - ISSN 0716-7725-Valparaíso, Chile 


\begin{tabular}{|c|c|}
\hline $\begin{array}{l}\text { Defensoría Penal } \\
\text { Pública. }\end{array}$ & $\begin{array}{l}\text { Ejecución de la pena, Principio de legalidad, Garantías } \\
\text { constitucionales, Libertad personal, Defensa, Género, Autonomía, } \\
\text { Inocentes. }\end{array}$ \\
\hline INDH & $\begin{array}{l}\text { Hacinamiento, Derechos, Penas alternativas, Aislamiento, } \\
\text { Gendarmería, Derechos fundamentales. }\end{array}$ \\
\hline $\begin{array}{l}\text { Fiscal Corte } \\
\text { Suprema. }\end{array}$ & $\begin{array}{l}\text { Población penal, Hacinamiento, Encierro, Actividades, Condiciones } \\
\text { sanitarias, Política criminal, Aislamiento, Gendarmería, } \\
\text { Alimentación, Educación, Capacitación, Rehabilitación, Derechos } \\
\text { Humanos, Libertades fundamentales, Obligación, Reincorporación, } \\
\text { Reincidencia. }\end{array}$ \\
\hline Centro DDHH - UDP & $\begin{array}{l}\text { Hacinamiento, Población penal, Derechos Humanos, Encierro, } \\
\text { Descriminalizar, Reinserción, Pobres, Decisión Política, Represión, } \\
\text { Política Criminal, Trato igualitario, Marginalidad, Discriminación, } \\
\text { Jóvenes, Proporcionalidad, Justicia especializada. }\end{array}$ \\
\hline Risolidaria & $\begin{array}{l}\text { Circunstancias, Desempleo, Familias disfuncionales, Rehabilitación, } \\
\text { Reinserción, Personas, Sociedad civil, Trabajos comunitarios. }\end{array}$ \\
\hline CLADEM & $\begin{array}{l}\text { Transparencia, Cárcel, Contratos de concesión, Costo, Vulneraciones, } \\
\text { Mujeres presas, Mujeres visitas, Revisiones denigrantes, Salud, } \\
\text { Contacto con terceros, Pobreza, Drogas, Violencia intrafamiliar, } \\
\text { Gendarmería. }\end{array}$ \\
\hline $\begin{array}{l}\text { Alianza por Chile. } \\
\text { (Derecha) }\end{array}$ & $\begin{array}{l}\text { Lucha, Delitos, Policías, Dotación policial, Atribuciones policiales, } \\
\text { Prevención, Drogas, Rehabilitación, Narcotráfico, Jueces, Prisión } \\
\text { preventiva, Observatorio de jueces, Reincidentes. }\end{array}$ \\
\hline $\begin{array}{l}\text { Nueva Mayoría. } \\
\text { (Centro izquierda) }\end{array}$ & $\begin{array}{l}\text { Dotación policial, Riesgo social, Drogas, Ministerio Público, Análisis } \\
\text { delictual, Infraestructura, Hacinamiento, Prevención, Persecución } \\
\text { penal, Justicia juvenil, Programa laboral, Especialización. }\end{array}$ \\
\hline $\begin{array}{l}\text { Enríquez Ominami. } \\
\text { (izquierda moderada). }\end{array}$ & $\begin{array}{l}\text { Cifras, Miedo, Drogas, Prevención, Segregación urbana, } \\
\text { Rehabilitación, Reinserción. }\end{array}$ \\
\hline Sfeir (ecologista) & Cárceles, Reincidencia, Integración, Apoyo comunitario. \\
\hline Israel (Liberal) & $\begin{array}{l}\text { Vandalismo, Medidas alternativas, Espacios públicos, Dotación } \\
\text { policial, Seguridad privada. }\end{array}$ \\
\hline $\begin{array}{l}\text { Jocelyn Holt. } \\
\text { (independiente } \\
\text { conservador) }\end{array}$ & Despenalización de marihuana, Drogas. \\
\hline
\end{tabular}

Facultad de Derecho y Ciencias Sociales - Universidad de Valparaíso - Chile 
Cuando procedemos a analizar la frecuencia con que cada uno de estos conceptos es reiterado por los diferentes emisores resultan una serie de cosas llamativas y preocupantes.

\begin{tabular}{|l|c|}
\hline Topois & Frecuencia. \\
\hline Policía, Dotación policial. & $\mathbf{1 0}$ \\
\hline Drogas. & 5 \\
\hline Cárcel. Prevención. Reincidencia. & 4 \\
\hline Hacinamiento. Jueces. Ministerio Público. Reinserción. & 3 \\
\hline $\begin{array}{l}\text { Capacitación. Concesión. Costo/beneficio. Flexibilidad. Gendarmería. } \\
\text { Rehabilitación. }\end{array}$ & 2 \\
\hline $\begin{array}{l}\text { Aislamiento. Derechos Humanos. Descentralización. Género. Percepción. } \\
\text { Población Penal. Pobres. Política criminal. Prevención temprana. Rendición } \\
\text { de cuentas. Transparencia. Victimización. }\end{array}$ & \\
\hline Todos los demás conceptos arriba desagregados obtienen solo una mención. & \\
\hline
\end{tabular}

La apelación a la Policía como principal actor de la política criminal es evidente. Pero frente a la muy menor mención de Gendarmería, encargada de la rehabilitación, permiten observar que no existe en verdad una política criminal y penitenciaria integral sino subsumida en una política fuertemente trazada por la lógica policial, que es transversal: diez de los quince emisores apelan a ella.

Prevención es la mitad que la persecución; hacinamiento es apenas un cuarenta por ciento de la policía; incluso la propuesta ideológica de costo/beneficio es un tercio que su herramienta de ejecución. Esto se traspasa al proyecto de ley de presupuesto, que para 2012 entrega a Carabineros de Chile un presupuesto anual de US $\$ 1.638$ millones, a la Policía de Investigaciones US\$ 408 millones (US $\$ 2.046$ sumados), mientras que a Gendarmería de Chile ni siquiera aparece desagregada sino subsumida en el Ministerio de Justicia y en materia carcelaria solo aparece lo que se asignará a cárceles concesionadas ${ }^{65}$.

65. http://www.hacienda.cl/especiales/presupuesto/presupuesto-2012/proyectopresupuesto-2012.html (visita 21 de Octubre de 2010).

Revista de Ciencias Sociales - Número 63 (2013) - Universidad de Valparáíso - ISSN 0716-7725-Valparaíso, Chile 
Esta apelación a la acción policial por sobre la integralidad jurídica resulta preocupante, tanto en términos de ratio como del lugar que se concede en importancia sistémica al poder judicial y al rol de los jueces, quienes para los sectores más conservadores que dominan la agenda discursiva se les considera meros encarceladores: Las propuestas de restringir legalmente los otorgamientos de libertades, aumentar la capacidad de intervención policial sin control judicial, un observatorio de comportamiento jurisdiccional sobre la libertad decisoria del poder judicial y restringirlo a un decisionismo pre establecido constituyen un agravio directo a la independencia judicial. Estas orientaciones constituyen una verdadera inversión ideológica del estado de derecho en la medida que subordinan la razón jurídica a la razón del orden público y del control social.

La mayor atribución y centralidad de la policía constituyen una direccionalidad de lo arbitrario tanto hacia la población como hacia la institucionalidad democrática. La definición misma del orden público es problemática y fuertemente dependiente de la decisión política coyuntural, sujeta a lobby y a una política más mediática que efectiva. "Teóricamente, cabe a la policía ejercer la vigilancia de la población, encargándose de la mantención del “orden público”. En estas actividades, donde se ejerce el poder de policía del Estado, quién lo ejerce tiene discrecionalidad, o discreción. Eso quiere decir que, en un continuo donde en un polo está la arbitrariedad o abuso de poder y, en el otro, la acción realizada conforme a la letra de la ley, la autoridad toma actitudes para garantizar la seguridad de la población que son discrecionales. Tales actitudes son de carácter preventivo, esto es, ejercidas antes de consumarse el hecho delictuoso o prejudicial" ${ }^{\prime 6}$.

66. KANT DE LIMA, Roberto. Ensaios de Antropologia e de Direito. Lumen Juris Editora. Río de Janeiro. 2011. Págs. 50-51. En el original: Teoricamente, ele deve ser a vigilância policial da população e são responsáveis pela manutenção da “ordem pública”. Em todas estas actividades, onde o poder é exercido pela polícia de estado, que exerce, tem poder discricionário, ou discrição. Em todas estas actividades, onde o poder é exercido pela polícia de estado, que exerce, tem poder discricionário, ou discrição. Isso significa que, em um continuum onde um pin é uma arbitrariedade ou abuso de poder e, por outro lado, a ação foi realizada de acordo com a letra da lei, A autoridade vai tomar atitudes para garantir a segurança da população que são

Facultad de Derecho y Ciencias Sociales - Universidad de Valparaíso - Chile 
La población queda así expuesta a un poder al límite de lo institucional, sujeto al mando institucional y no a criterios de racionalidad jurídica fundada. Se configura a la vez una inversión de sentido de la institucionalidad democrática toda vez que el ciudadano que elige sus autoridades y paga impuestos merece contraprestaciones de seguridad social y no sólo de orden público. Ya no se trata sólo del espacio carcelario como un espacio de vigilancia sino que se ha extendido la razón del orden y control a la sociedad completa. Esta transversalidad de discursos que privilegia a la policía como herramienta de seguridad pública y oscurece sociedad y cárcel deviene en un continuo de la forma que lo exponía Michel Foucault cuando señalaba que "Prisión y Policía forman un dispositivo gemelo, cada una de ellas por sí sola realiza en todo el campo de las ilegalidades la diferenciación, el aislamiento y la utilización de una delincuencia. En las ilegalidades, el sistema policía-prisión corresponde a una delincuencia manejable. Esta, con su especificidad, es un efecto del sistema: pero también se torna un engranaje, un instrumento de aquel. De manera que en verdad se debería hablar de un conjunto cuyos tres elementos (policía-prisión-delincuencia) se apoyan unos sobre los otros $y$ forman un circuito que nunca se interrumpe. La vigilancia policial alimenta a la prisión de los infractores que esta transforma en delincuentes, objetivos y auxiliares de los controles policiales que regularmente envían a algunos de ellos de regreso a prisión" ${ }^{7}$.

discricionárias. Tais atitudes são de natureza preventiva, isto é, exercida antes consumou o delito ou prejudicial.

67. FOUCAULT, Michelle: Vigiar e punir. (Vigilar y Castigar). Vozes. Petrópolis. 1987. Pág. 248. En el original: "Prisão e a polícia forma uma dupla dispositivo, cada uma delas por si só executa em todo o campo de ilegalidades diferenciação, o isolamento e o uso de um crime. A ilegalidades, o sistema policial-prisão corresponde a um nível controlável crime. Este, com a sua especificidade, é um efeito do sistema, mas também se torna uma marcha, um instrumento de que. De tal forma que a verdade deve ser falar de um conjunto cujos três elementos (polícia-prisão-crime) são compatíveis uns com os outros e formam um circuito que nunca quebra. A vigilância policial alimenta a prisão dos criminosos que se transforma em criminosos, tem como objetivo auxiliar e controlos de polícia enviar regularmente alguns dos-los de volta à prisão.

Revista de Ciencias Sociales - Número 63 (2013) - Universidad de Valparáíso - ISSN 0716-7725-Valparáiso, Chile 
Pero adicionalmente queda de manifiesto cómo aquellos conceptos que dicen relación con las garantías, los derechos, los derechos humanos, las libertades fundamentales, el debido proceso, la independencia judicial, las relaciones sociales y las personales entre reos, familia, comunidad y entorno quedan en desuso, lo que no es casual sino revela una ideología de lo criminal y de lo penitenciario que contando y haciendo uso de recursos institucionales y mediáticos busca denunciar y vigilar, pero no enunciar y solucionar. De los 135 conceptos extractados, 88 de ellos que en su mayoría dicen relación con contexto social, defensa de derechos fundamentales, libertades, medidas de prevención y reinserción quedan solo son mencionados una vez, y casi todos ellos por los entes del estado o de la sociedad civil que no forman el centro de la decisión política de corte conservador.

Más decepcionante resulta el considerar que los Derechos Humanos ocupan solo una quinta parte de las menciones que la policía y solo un tercio de las referencias a las drogas y a la cárcel. Ciertamente no estamos frente a una sociedad centrada y que valorice los derechos humanos y con ello los derechos de las personas y las obligaciones que entre ciudadanos, estado y entre ellos mismos en tanto comunidad deben y pueden configurarse y existir.

Particularmente preocupante es la mención extraordinaria que se hace a las drogas como el factor de mayor peligrosidad o incidencia en la permanencia del campo delictual. Ninguno de los informes que la citan aportan cifras o referencias a otros estudios que permitan definir esa como la actual causa más importante de la delincuencia o si es una causa concomitante más, un deshinibidor de conductas o un bloqueamiento psicosocial de la razonabilidad costo/beneficio que lleva a decidir entre delinquir o no delinquir. Incluso si se tiene a la vista documentos que se referirían a la materia de la ya citada Paz Ciudadana ${ }^{68}$ puede concluirse de manera definitiva que es el gran responsable de la delincuencia:

68. MERTZ, Catalina. Delincuencia en Chile: diagnóstico y propuestas. Fundación

Paz Ciudadana. Santiago. 2012. http://95 propuestas.cl/site/wp-content/ uploads/2013/05/delincuencia-en-chile-diagnostico-y-propuestas-catalina-mertz.pdf (visita 21 de Octubre de 2013).

Facultad de Derecho y Ciencias Sociales - Universidad de Valparaíso - Chile 
"En relación al consumo de drogas, una publicación del año 2008 del entonces Conace, ahora Senda, resume los estudios publicados hasta ahora sobre el consumo de drogas en población penal, y de acuerdo al cual se concluye en términos generales que el consumo problemático de alcohol y drogas es más prevalente en esta población que en la población general, y el consumo de pasta base estaría especialmente ligado al robo" ${ }^{69}$.

El resto del documento se refiere a una relación entre juventud marginal, consumo de drogas (especialmente cocaína y pasta base o crack) y la necesidad de políticas de rehabilitación efectivas y lo asocia a una forma de prevención temprana, pero no entrega ningún antecedente serio, cuantitativo ni cualitativo, que indique que la droga es el gran detonante de la delincuencia. Ni siquiera con el Décimo Estudio Nacional de Drogas en Población General, publicado en Octubre de 2013 por el SENDA, Servicio Nacional para la Prevención y Rehabilitación del Consumo de Drogas y $\mathrm{Alcohol}^{70}$ es posible llegar a esas conclusiones alarmistas y deterministas. Si bien ha incluido este año un pequeño acápite sobre consumo y Percepción de Problemas en el Barrio, sumados al del Trastorno no asociado al consumo de sustancias puede darse lugar a una imagen de este problema como si fuese el principal problema de Chile. De hecho el efecto de que trata es la adicción y no otros.

En materia de efectos en el barrio tampoco arroja datos significativos, ya que primero vuelve a enfrentar el problema de la percepción y no el de la realidad; y en segundo lugar concluye que hay tráfico, robos, venta clandestina de alcohol y balaceras pero los principales efectos son de rayados en las paredes y jóvenes no haciendo nada, pero no explica causas ni hace un puente metodológico que permita traducir la percepción en números y en causas de un aumento explosivo en la delincuencia.

Falta en ese razonamiento un estudio profundo del por qué los jóvenes tienen tiempo libre y qué podrían hacer con él, así como del

69. Ídem. Pág. 44. El subrayado es nuestro.

70. www.senda.gob.cl/observatorio/estudios/poblacion-general/decimo-estudiopoblacion-general/ (visita 22 de Octubre de 2013).

Revista de Ciencias Sociales - Número 63 (2013) - Universidad de Valparáíso - ISSN 0716-7725-Valparáiso, Chile 
por qué hacen su vida en las calles y no en las casas, de la habitabilidad colectiva de las viviendas y sus condiciones de intimidad, entre otras.

Se trata en verdad de una conclusión elaborada de antemano, una conclusión seudocientífica y sin evidencia suficiente de respaldo, apuntes que son en verdad ideología.

Lo anterior es preocupante porque más bien indican que lo que se está construyendo es un nuevo enemigo interno de poca densidad y disperso en el territorio como para justificar una serie de acciones también menores pero rentables comunicacionalmente, ya que expresamente se excluye de ese estudio el narcotráfico de gran escala, para enfocar allí, en ese espacio de venta/consumo de drogas no organizado algún tipo de guerra de baja pero dura intensidad contra este enemigo científicamente indeterminable.

Revisando el siguiente gráfico que despliega en un espacio visual los discursos, sus topois y la importancia que a cada ítem se le otorga, además de la desproporción del "enemigo" drogas en un país que no tiene una verdadera política de substancias, inlcuyendo el alcohol, lo que incluye la carencia de centros públicos de tratamiento efectivo para quienes necesiten desintoxicación, que permitan materializar el teórico derecho a la salud reconocido constitucionalmente, la mayoritaria preeminencia de la policía frente a otros elementos de mayor integralidad a la hora de establecer derechos y definir políticas públicas, en un estado que se dice democrático, nos lleva a otras reflexiones,

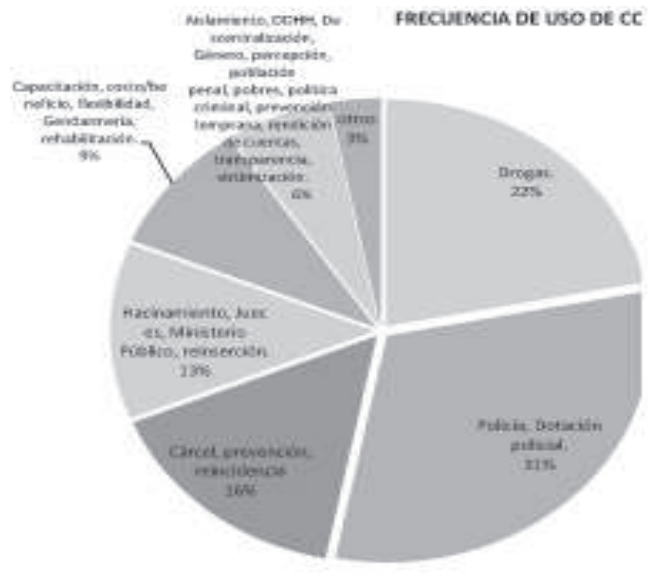

Facultad de Derecho y Ciencias Sociales - Universidad de Valparaíso - Chile 
Ya en un sentido de construcción de estos discursos es necesario decir que el uso del concepto de percepción no es científico sino una construcción lingüística que ante la falta de otras cifras duras que no se tienen, sobre las que no existen estudios, se usa como sustento metodológico para justificar premisas ideológicas.

Intentemos aún una posibilidad más de análisis y procedamos a desplegar los conceptos en un campo de descripción de los principales topois de los discursos expuestos en un plano de campo con cuatro puntos cardinales que se forman a partir de los 4 tipos de discursos conceptuales que describimos y sus discursos: represivo, institucional, relacional y garantista.

El resultado es uno de corte piramidal, con la policía, las drogas y la cárcel en su cima y con notorio desplazamiento hacia el margen inferior de los derechos humanos y los principios tradicionales del derecho penal clásico, ya ni siquiera de uno garantista, como son las ideas de una debida defensa, garantías constitucionales o la igualdad ante la ley.

Toda esta exposición nos permiten ya tener una visión de campo lo suficientemente amplia como para advertir de algunas cuestiones fundamentales:

El despoblamiento del campo de los derechos y la condensación de las instituciones bajo la dirección de la represión quedan en evidencia.

\section{CAMPO TOPOLÓGICO}

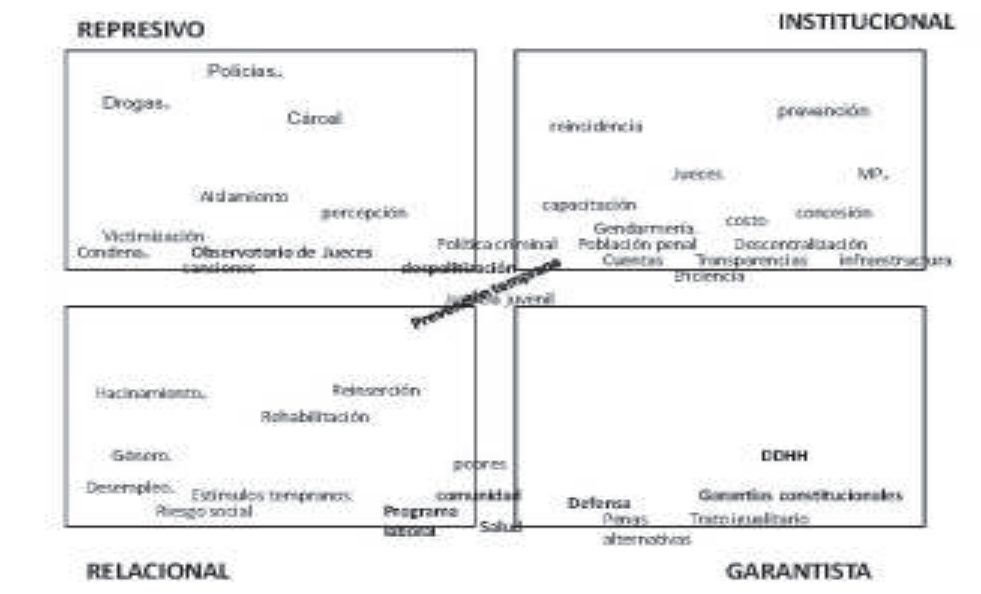

Revista de Ciencias Sociales - Número 63 (2013) - Universidad de Valparáíso - ISSN 0716-7725-Valparaíso, Chile 


\section{Algunas conclusiones provisorias}

La Política de Seguridad Pública reposa en construcciones artificiales, no en datos duros de tipos de delitos versus daño social que ocasionan (contra la propiedad individual $\mathrm{v} / \mathrm{s}$ delitos de cuello blanco por ejemplo), política organizada desde discursos performadores centrados en la represión y en la regulación del orden. Se atiende a los efectos no a las causas, eso es la precepción y el miedo. El discurso hegemónico señala que es necesaria una posición de fuerza como política criminal antes que derechos procesales, derechos sociales y soluciones materiales y relacionales. Esta construcción de la seguridad pública entiende que se satisface el estado de derecho con leyes más rígidas y no más integración material y derechos, privilegiando la razón policial por sobre una razón democrática. De allí solo pueden derivar políticas públicas atomísticas, de fuerte carácter moralista, generadoras de una percepción del miedo, aumento de gasto público y privado en implementos de seguridad, sistemas de vigilancia y cárceles concesionadas privilegiando mercado sobre comunidad y control por sobre un sistema de derechos fuerte. Más seguridad, más mercado, menos estado social. "La penalidad neoliberal presenta la siguiente paradoja; pretende remediar con 'mas Estado' policial o penitenciario el 'menos Estado' económico y social que es la causa directa de la escalada generalizada de la inseguridad objetiva y subjetiva en todos los países, tanto del Primero como del Segundo Mundo"71.

No existe sobre el conjunto de la política criminal una perspectiva de derechos humanos ni de obligaciones relacionales estado sociedad. La ausencia de una perspectiva derechos para el accionar del estado pone seriamente en duda que estemos frente a un estado de derecho que incluya su dimensión jurídico social y no solo la esfera dogmáticoformal del derecho. Trabajar en un sentido inverso nos obliga a cambiar

71. WACQUANT, Löic. As Prisoes da Miséria. Jorge Zahar Editor. Río de Janeiro. 2001. Pág. 7. En el original: A penalidade neoliberal apresenta o seguinte paradoxo: pretende-se corrigir com "mais" polícia de Estado ou prisão o "menos" situação económica e social que é a causa direta do agravamento da insegurança generalizada no objectivo e subjectivo todos os países, tanto do primeiro como do Segundo Mundo.

Facultad de Derecho y Ciencias Sociales - Universidad de Valparaíso - Chile 
la mirada, a reobservar el cuadro de campo que nos muestra el orden de distribución de las ideas democráticas y centradas en los derechos, para así reordenar los discursos y el tipo de políticas que se generan, de manera que nos permita apreciar en qué campos habría que construir y qué ideas volver relevantes si se pretende hacer una política normativa y social diferente.

En ese escenario es que los discursos y prácticas que se refieren a los derechos humanos, a los derechos y garantías legales, las prácticas de derechos y libertades fundamentales para quienes se enfrentan al sistema penal y que tienden a adoptar un urgente pero a su vez marcado carácter de contención sobre la arbitrariedad y el poder deben pasar a un proceso de construcción afirmativo. Construcción de pensamiento, indicadores, datos reales y complejos, ya no criterios a-científicos como la percepción, la victimización y una naturalización neo-lombrossiana.

Pensar los derechos humanos y la ciudadanía más allá de la contención sino como una propuesta de construcción de sentido y de prácticas es una tarea al debe de las políticas criminales y penitenciarias centradas en las necesidades y los derechos. Las propuestas para una ciudadanía integradora son otra historia por vitalizar, una que, como el cantor riograndense Víctor Ramíl parece decir "Não estamos à margem de um centro, mas no centro de uma outra história"72.

\section{Bibliografía}

BACHELET, Michel. No podemos seguir enfrentando el problema con slogans de campaña. www.cooperativa.cl 24-09-3013.

BEYER, Harald. VERGARA, Rodrigo. Delincuencia en Chile: determinantes y rol de las políticas públicas. Pontificia

Universidad Católica de Chile. Santiago. 2006.

BUTLER, Judith. El Género en disputa. Feminismo y la subversión de la identidad. Ediciones Paidós Ibérica S.A. Barcelona. 2007.

72. RAMÍL,Víctor: "No estamos al margen de un centro, sino en el centro de una otra historia". http://www.agenciariff.com.br/site/AutorCliente/Autor/75 (visita 21 de Octubre de 2013).

Revista de Ciencias Sociales - Número 63 (2013) - Universidad de Valparáíso - ISSN 0716-7725-Valparáiso, Chile 
CHIES, Luiz Antonio: A questao penitenciária. En Tempo Social. Revista de sociología da Universidad de Sao Paulo. Volúmen 25, $\mathrm{N}^{\circ} 1.2013$.

DEFENSORÍA PENAL PÚBLICA. Cuenta Pública del Defensor Público Nacional del año 2012 en la página web oficial de la

Defensoría www.dpp.cl

ENRÍQUEZ OMINAMI, Marco. www.theclinic.cl

ESPINA, Alberto. http://www.lanacion.cl/espina-y-la-delincuencia-secreo-una-expectativa-muy-alta/noticias/2013-08-02/210218.html 2 de agosto de 2013.

FOUCAULT, Michelle. Vigiar e punir. (Vigilar y Castigar). Vozes. Petrópolis. 1987.

\section{FUNDACIÓN PAZ CIUDADANA}

- Evaluación del sistema concesionado versus el sistema tradicional en la reducción de la reincidencia delictual. Junio 2013.

- Conceptos. Abril de 2013.

- Conceptos. Marzo de 2013.

- La Tercera Generación De Políticas Públicas De Seguridad Que Chile Necesita. Septiembre 2013.

- Memoria 2012.

- Balance de la delincuencia 2012. Mayo de 2013.

HERRERA, Marcela. Informe de Mujeres Privadas de Libertad en Chile. Elaborado por el Grupo de Enlace de CLADEM en ChileMarcela Herrera. www.cladem.org

HINZPETER, Rodrigo. A dos Años de Gobierno. Lanacion.cl 24 de enero de 2012.

INSTITUTO NACIONAL DE DERECHOS HUMANOS. Informe anual de Derechos Humanos 2012. www.indh.cl

ISRAEL, Ricardo. ricardoisraelpresidente2014.blogspot.com.br (visita 18 de Octubre de 2013).

JOCELYN HOLT, Tomás. www.tomaspresidente.cl/compromiso-decampana-tomas-2014-plan-joven-y-despenalizacion/

Facultad de Derecho y Ciencias Sociales - Universidad de Valparaíso - Chile 
KANT DE LIMA, Roberto. Ensaios de Antropologia e de Direito. Lumen Juris Editora. Río de Janeiro. 2011.

\section{LIBERTAD Y DESARROLLO}

- Cárceles Concesionadas. Revitalizando el Modelo. 2012.

- Temas Públicos. No 1.08816 de noviembre de 2012.

- Temas Públicos. No 1.09718 de enero de 2013.

- Temas Públicos. No 1.10328 de marzo de 201.

- Temas Públicos. No 1.10512 de abril de 2013.

MALDONADO CROQUEVIELLE, Mónica. Informe presentado en virtud de la invitación de la Comisión de Constitución, Legislación, Justicia y Reglamento del Senado de la República, a la sesión a celebrarse el día $1^{\circ}$ de junio de 2009, para considerar los diversos problemas que afectan al funcionamiento del sistema carcelario en nuestro país.

MATTHEI, Evelyn. www.rn.cl/v1/component/k2/item/5982-evelynmatthei-presento-sus-propuestas-de-seguridad-publica-conenfasis-en-prevencion-y-mano-firme www.senda.gob.cl/observatorio/ estudios/poblacion-general/decimo-estudio-poblacion-general/ MERTZ, Catalina. Delincuencia en Chile: diagnóstico y propuestas. Fundación Paz Ciudadana. 2012. http://95propuestas.cl/site/wpcontent/uploads/2013/05/delincuencia-en-chile-diagnostico-ypropuestas-catalina-mertz.pdf

MINISTERIO DE HACIENDA. Gobierno de Chile. http://www. hacienda.cl/especiales/presupuesto/presupuesto-2012/proyectopresupuesto-2012.html (visita 21 de ctubre de 2010).

MIRANDA, Roxana www.roxanamiranda.cl

RAMÍL,Víctor: "No estamos al margen de un centro, sino en el centro de una otra historia". http://www.agenciariff.com.br/site/ AutorCliente/Autor/75

SFEIR, Alfredo. www.Sfeir2014.cl/programa-presidencial\# page $=I X$ SHUBERT, Georgy. www.latercera.com/noticia/nacional/2013/07/680535059-9-georgy-shubert-defensoria-debe-poder-asistir-a-loschilenos-en-corte.sthml

Revista de Ciencias Sociales - Número 63 (2013) - Universidad de Valparáíso - ISSN 0716-7725-Valparaíso, Chile 
UNIVERSIDAD DIEGO PORTALES. Centro de Derechos Humanos. http://www.derechoshumanos.udp.cl/informe-anual-2012/

VIAL, Paula. 14-04-2011. http://www.latercera.com/noticia/nacional/ 2011/04/680-358522-9-defensora-nacional-exige-reformar-elsistema-de-penas-en-chile.shtml

WACQUANT, Lóic. As prisoes da miseria. Jorge Zahar Editor. Río de Janeiro. 2001.

\section{Otras páginas web}

www.lyd.com

www.michellebachelet.cl/seguridad/

www.pazciudadana.cl

www.risolidaria.cl

www.to2alamoneda.cl 